\title{
Stability of Steel Columns with Non-Uniform Cross-Sections
}

\author{
Theodore G. Konstantakopoulos, Ioannis G. Raftoyiannis* and George T. Michaltsos
}

Department of Civil Engineering, National Technical University of Athens, Athens 15780, Greece

\begin{abstract}
In this work, non-uniform steel members with or without initial geometrical or loading imperfections, that are loaded by axial forces applied concentrically or eccentrically and by concentrated moments applied at the ends or at intermediate points, are studied. More specifically, steel members with varying cross-sections, tapered or stepped or members consisting by two different tapered parts are considered. The formulation presented in this work is based on solving the governing equation of the problem through a numerical method where the eigenshapes of the member are employed. A failure plasticity criterion is introduced for members especially the short ones that will never reach the elastic critical buckling load. Although only the simply supported beam-column case is studied herein, it is obvious that the method can be extended to multi-span beams and frames, by employing the corresponding eigenshapes. Useful diagrams are presented for both the critical buckling loads and the equilibrium paths showing the influence of the main characteristics of the beam-column.
\end{abstract}

Keywords: Steel columns, stability, non-uniform members, buckling loads, imperfections, yield failure.

\section{INTRODUCTION}

The use of steel members with non-uniform crosssections either as columns or as distressed parts of a structure with or without bending moments is very common in steel constructions. There is a wide variety of structures such as buildings frames, bridge members, masts or cranes, etc, which are designed with members of non-uniform crosssections in order to minimize the required material. The significance of using such members in structures and the necessity to study their structural behavior has been realized since the beginning of the $19^{\text {th }}$ century by A. Föppl, as it was referenced by Timoshenko [1].

A first approach and study of the above-mentioned problems of columns with variable cross-sections was made by Dinkik in 1914 and in 1916. The main results of these studies were translated in English by Malets [2,3]. The same problem was studied by Ostwald [4], by Ono [5], by Stedman [6] and by Morley [7, 8]. On the history of early studies on these topics, one can refer to Timoshenko [9].

Bleich [10] studied compression members the crosssectional moment of inertia of which was varying by a halfsine curve. On the other hand, the significance of the initial imperfections was noted very early and studied mainly experimentally by Marston [11], by Jensen [12] and by Lilly [13], the studies of which were gathered by Salmon [14]. A significant study of compression stepped columns consisting by two parts through the use of the Galerkin method has been presented by Dimitrof [15].

There is a relatively large number of theoretical or experimental publications on tapered or stepped columns with or without imperfections [16-31]. In the present paper,

*Address correspondence to this author at the Civil Engng Dept., National Technical University of Athens, 15780 Greece; Tel: +30-210-7722454; Fax: +30-210-7722482; E-mail: rafto@central.ntua.gr non-uniform steel members with or without imperfections (of any form), loaded by axial forces (concentrically or eccentrically applied) and by concentrated moments applied at its ends or intermediate points are studied. The steel members with cross-section that may vary along the length, can be tapered or stepped or they can be members consisting by two unequal tapered parts. The imperfections considered may have any form. The formulation presented in this paper is based on solving the governing equation of the problem through the Galerkin method using the eigenshapes of the member. A plasticity failure criterion is introduced for stub or short members that will never reach the elastic critical buckling load. Although in this paper only the simply supported single-span beam-column is studied, it is obvious that the formulation presented may be extended to any type of frame members or frames using the corresponding eigenshapes.

The results are presented in the form of diagrams either for the critical buckling loads or for the equilibrium paths, showing the influence of the main member's characteristics, as for example the cross-sectional variation law, the intermediate loads and bending moments or the existing imperfections on the above mentioned buckling loads and equilibrium paths.

Although these diagrams are derived for a simply supported beam-column they can be readily employed for the design of steel frames with such members through the use of the equivalent buckling length factor concept.

\section{GOVERNING EQUATIONS}

Let us consider the beam-column shown in Fig. (1), where the cross-section varies along the length (x-axis) according to a known shape (parabolic, tapered, stepped etc). The considered member is loaded by forces and moments as shown in Fig. (1). Moreover, the member may have an initial imperfection $\mathrm{w}_{\mathrm{o}}(\mathrm{x})$. 


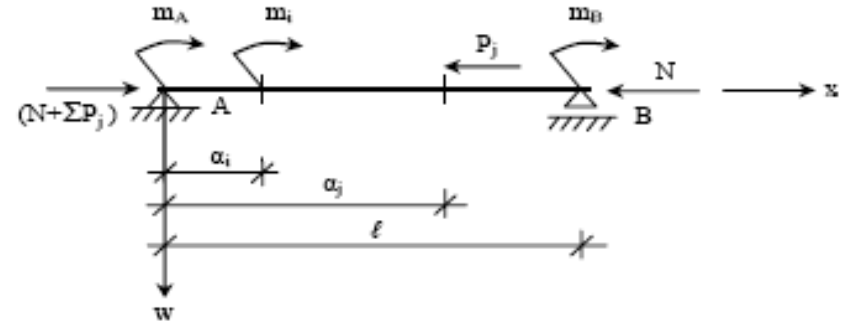

Fig. (1). Forces and moments on a beam-column.

In addition, we assume that the member is laterally supported and hence, it is protected against the possibility of buckling about the weak axis. The differential equation for buckling of the beam-column is given as follows:

$$
\begin{aligned}
{\left[\mathrm{EI}(\mathrm{x}) \mathrm{w}^{\prime \prime}\right]^{\prime \prime}+\mathrm{N}\left(\mathrm{w}+\mathrm{w}_{\mathrm{o}}\right)^{\prime \prime}+} & \\
+\sum_{\mathrm{j}} \mathrm{P}_{\mathrm{j}}\left(\mathrm{w}+\mathrm{w}_{\mathrm{o}}\right)^{\prime \prime} & {\left[1-\mathrm{H}\left(\mathrm{x}-\alpha_{\mathrm{j}}\right)\right]-} \\
& -\sum_{\mathrm{i}} \mathrm{m}_{\mathrm{i}} \delta^{\prime}\left(\mathrm{x}-\alpha_{\mathrm{i}}\right)=0
\end{aligned}
$$

where EI is the bending rigidity of the member, $w$ is the deflected shape, $\mathrm{w}_{\mathrm{o}}$ is the initial imperfection, $\mathrm{N}$ is the externally applied axial force, $\mathrm{P}_{\mathrm{i}}$ and $\mathrm{m}_{\mathrm{i}}$ are concentrated forces and moments applied at intermediate positions over the length, $\mathrm{H}(\mathrm{x})$ is the Heaviside unit step function and $\delta(\mathrm{x})$ the Dirac delta function.

The above equation may be written as follows:

$$
\begin{aligned}
& \mathrm{E} \mathrm{Iw}^{\prime \prime \prime}+2 \mathrm{EI} \mathrm{I}^{\prime \prime \prime}+\mathrm{EI} \mathrm{I}^{\prime \prime} \mathrm{w}^{\prime \prime}+\mathrm{Nw}^{\prime \prime}+ \\
& +\sum_{\mathrm{j}} \mathrm{P}_{\mathrm{j}} \mathrm{w}^{\prime \prime}\left[1-\mathrm{H}\left(\mathrm{x}-\alpha_{\mathrm{j}}\right)\right]=-\mathrm{Nw}_{\mathrm{o}}^{\prime \prime}- \\
& -\sum_{\mathrm{j}} \mathrm{P}_{\mathrm{j}} \mathrm{w}_{\mathrm{o}}^{\prime \prime}\left[1-\mathrm{H}\left(\mathrm{x}-\alpha_{\mathrm{j}}\right)\right]+\sum_{\mathrm{i}} \mathrm{m}_{\mathrm{i}} \delta^{\prime}\left(\mathrm{x}-\alpha_{\mathrm{i}}\right)
\end{aligned}
$$

Non-existence of moments and initial imperfection leads to a homogeneous differential equation (without second member), which gives the buckling critical loads, while existence of moments and initial imperfections leads to a complete differential equation, which allows us to study the equilibrium paths.

We are searching for a solution in the following form:

$\mathrm{w}(\mathrm{x})=\mathrm{c}_{1} \mathrm{X}_{1}(\mathrm{x})+\mathrm{c}_{2} \mathrm{X}_{2}(\mathrm{x})+\cdots \cdots+\mathrm{c}_{\mathrm{n}} \mathrm{X}_{\mathrm{n}}(\mathrm{x})$

where $X_{n}(x)=\sin (n \pi x / \ell)$ are the eigenshapes of the simply supported beam and $\mathrm{c}_{\mathrm{n}}$ are constants to be determined.

Introducing eq(3) into eq(2) we obtain:

$$
\begin{aligned}
& \mathrm{EI} \sum_{\rho} \mathrm{c}_{\rho}\left(\frac{\rho \pi}{\ell}\right)^{4} \sin \frac{\rho \pi \mathrm{x}}{\ell}-2 \mathrm{EI}^{\prime} \sum_{\rho} \mathrm{c}_{\rho}\left(\frac{\rho \pi}{\ell}\right)^{3} \cos \frac{\rho \pi \mathrm{x}}{\ell}- \\
& -\mathrm{EI} \sum_{\rho}^{\prime \prime} \mathrm{c}_{\rho}\left(\frac{\rho \pi}{\ell}\right)^{2} \sin \frac{\rho \pi \mathrm{x}}{\ell}-\mathrm{N} \sum_{\rho} \mathrm{c}_{\rho}\left(\frac{\rho \pi}{\ell}\right)^{2} \sin \frac{\rho \pi \mathrm{x}}{\ell} \\
& -\sum_{\mathrm{j}}\left\{\frac{\mathrm{N}}{\mu_{\mathrm{j}}} \sum_{\rho} \mathrm{c}_{\rho}\left(\frac{\rho \pi}{\ell}\right)^{2} \sin \frac{\rho \pi \mathrm{x}}{\ell}\left[1-\mathrm{H}\left(\mathrm{x}-\alpha_{\mathrm{j}}\right)\right]\right\}= \\
& -\mathrm{Nw}_{\mathrm{o}}^{\prime \prime}-\sum_{\mathrm{j}} \frac{\mathrm{N}}{\mu_{\mathrm{j}}} \mathrm{w}_{\mathrm{o}}^{\prime \prime}\left[1-\mathrm{H}\left(\mathrm{x}-\alpha_{\mathrm{j}}\right)\right]+\sum_{\mathrm{i}} \mathrm{m}_{\mathrm{i}} \delta^{\prime}\left(\mathrm{x}-\alpha_{\mathrm{j}}\right)
\end{aligned}
$$

where we have set:

$\mathrm{P}_{\mathrm{j}}=\mathrm{N} / \mu_{\mathrm{j}}$

where $\mu_{\mathrm{i}}$ are the ratios of the loads $\mathrm{P}_{\mathrm{i}}$ over $\mathrm{N}$.

\section{BUCKLING LOADS}

By setting $\mathrm{w}_{\mathrm{o}}=0$ and $\mathrm{m}_{\mathrm{i}}=0$, eq( $\left.4 \mathrm{a}\right)$ becomes:

$$
\begin{aligned}
& \mathrm{EI} \sum_{\rho} \mathrm{c}_{\rho}\left(\frac{\rho \pi}{\ell}\right)^{4} \sin \frac{\rho \pi \mathrm{x}}{\ell}-2 \mathrm{EI}^{\prime} \sum_{\rho} \mathrm{c}_{\rho}\left(\frac{\rho \pi}{\ell}\right)^{3} \cos \frac{\rho \pi \mathrm{x}}{\ell}- \\
& -\mathrm{EI}{ }^{\prime \prime} \sum_{\rho} \mathrm{c}_{\rho}\left(\frac{\rho \pi}{\ell}\right)^{2} \sin \frac{\rho \pi \mathrm{x}}{\ell}-\mathrm{N} \sum_{\rho} \mathrm{c}_{\rho}\left(\frac{\rho \pi}{\ell}\right)^{2} \sin \frac{\rho \pi \mathrm{x}}{\ell}- \\
& -\sum_{\mathrm{j}} \frac{\mathrm{N}}{\mu_{\mathrm{j}}} \sum_{\rho} \mathrm{c}_{\rho}\left(\frac{\rho \pi}{\ell}\right)^{2} \sin \frac{\rho \pi \mathrm{x}}{\ell}\left[1-\mathrm{H}\left(\mathrm{x}-\alpha_{\mathrm{j}}\right)\right]=0
\end{aligned}
$$

Applying the Galerkin procedure in eq(5) and taking into account the orthogonality condition we obtain:

$$
\begin{aligned}
& \mathrm{c}_{1}\left(\mathrm{~A}_{\mathrm{k} 1}-\alpha_{\mathrm{k} 1} \mathrm{~N}\right)+\mathrm{c}_{2}\left(\mathrm{~A}_{\mathrm{k} 2}-\alpha_{\mathrm{k} 2} \mathrm{~N}\right)+\cdots+ \\
& +\mathrm{c}_{\mathrm{n}}\left(\mathrm{A}_{\mathrm{kn}}-\alpha_{\mathrm{kn}} \mathrm{N}\right)=0 \text { with } \mathrm{k}=1 \text { to } \mathrm{n}
\end{aligned}
$$

where:

$$
\begin{aligned}
\mathrm{A}_{\mathrm{k} \rho}= & \mathrm{E} \int_{0}^{\ell} \mathrm{I}(\mathrm{x})\left(\frac{\rho \pi}{\ell}\right)^{4} \sin \frac{\rho \pi \mathrm{x}}{\ell} \sin \frac{\mathrm{k} \pi \mathrm{x}}{\ell} \mathrm{dx}- \\
& -2 \mathrm{E} \int_{0}^{\ell} \mathrm{I}^{\prime}(\mathrm{x})\left(\frac{\rho \pi}{\ell}\right)^{3} \cos \frac{\rho \pi \mathrm{x}}{\ell} \sin \frac{\mathrm{k} \pi \mathrm{x}}{\ell} \mathrm{dx}- \\
& -\mathrm{E} \int_{0}^{\ell} \mathrm{I}^{\prime \prime}(\mathrm{x})\left(\frac{\rho \pi}{\ell}\right)^{2} \sin \frac{\rho \pi \mathrm{x}}{\ell} \sin \frac{\mathrm{k} \pi \mathrm{x}}{\ell} \mathrm{dx} \\
\alpha_{\mathrm{k} \rho}= & \frac{\rho^{2} \pi^{2}}{2 \ell}+\mu_{\mathrm{j}} \int_{0}^{\ell} \frac{\rho^{2} \pi^{2}}{\ell^{2}}\left(\sin \frac{\rho \pi \mathrm{x}}{\ell}\right)^{2}\left[1-\mathrm{H}\left(\mathrm{x}-\alpha_{\mathrm{j}}\right)\right] \mathrm{dx} \quad(\rho=\mathrm{k}) \\
\alpha_{\mathrm{k} \rho}= & \frac{\rho^{2} \pi^{2}}{2 \ell}+\mu_{\mathrm{j}} \int_{0}^{\ell} \frac{\rho^{2} \pi^{2}}{\ell^{2}} \sin \frac{\rho \pi \mathrm{x}}{\ell} \sin \frac{\mathrm{k} \pi \mathrm{x}}{\ell}\left[1-\mathrm{H}\left(\mathrm{x}-\alpha_{\mathrm{j}}\right)\right] \mathrm{dx}(\rho \neq \mathrm{k})
\end{aligned}
$$

In order that the above linear homogeneous system eq(6a) has non-trivial solutions the determinant of the coefficients of the unknowns $c_{\rho}$ must be equal to zero. This condition leads to the following eigenvalue problem expressed by the following equation:

$$
\left\|\mathrm{A}_{\mathrm{k} \rho}-\alpha_{\mathrm{k} \rho} \mathrm{N}\right\|=0
$$

Equation (7) gives the spectrum of the critical buckling loads $\mathrm{N}_{\mathrm{cr}}$.

\section{EQUILIBRIUM PATHS}

Equation (4) allows us to determine equilibrium paths. Applying once again the Galerkin procedure in eq(4) and taking into account the orthogonality condition we obtain:

$\mathrm{c}_{1}\left(\mathrm{~A}_{\mathrm{k} 1}-\alpha_{\mathrm{k} 1} \mathrm{~N}\right)+\mathrm{c}_{2}\left(\mathrm{~A}_{\mathrm{k} 2}-\alpha_{\mathrm{k} 2} \mathrm{~N}\right)+\cdots+$
$+\mathrm{c}_{\mathrm{n}}\left(\mathrm{A}_{\mathrm{kn}}-\alpha_{\mathrm{kn}} \mathrm{N}\right)=\mathrm{B}_{\mathrm{k}}$ with $\mathrm{k}=1$ to $\mathrm{n}$

where $A_{k \rho}$ and $\alpha_{k \rho}$ are given in eq(6b), while $B_{k}$ is given by the following equation:

$$
\begin{aligned}
\mathrm{B}_{\mathrm{k}}= & -\mathrm{N} \int_{0}^{\ell} \mathrm{w}_{\mathrm{o}}^{\prime \prime} \sin \frac{\mathrm{k} \pi \mathrm{x}}{\ell} \mathrm{dx}-\sum_{\mathrm{j}} \mu_{\mathrm{j}} \mathrm{N} \int_{0}^{\alpha_{\mathrm{j}}} \mathrm{w}_{\mathrm{o}}^{\prime \prime} \sin \frac{\mathrm{k} \pi \mathrm{x}}{\ell} \mathrm{dx}- \\
& -\sum_{\mathrm{i}} \mathrm{m}_{\mathrm{i}} \frac{\mathrm{k} \pi}{\ell} \cos \frac{\mathrm{k} \pi \alpha_{\mathrm{i}}}{\ell}
\end{aligned}
$$


From the system of equations (8a), we obtain the unknown constants $\mathrm{c}_{\rho}(\mathrm{N}), \quad(\rho=1$ to $\mathrm{n})$ and from eq(3) the equilibrium paths as follows

$\mathrm{w}(\mathrm{x})=\mathrm{c}_{1}(\mathrm{~N}) \sin \frac{\pi \mathrm{x}}{\ell}+\cdots+\mathrm{c}_{\mathrm{n}}(\mathrm{N}) \sin \frac{\mathrm{n} \pi \mathrm{x}}{\ell}$

\section{FAILURE CRITERION}

It is obvious that there are cases (especially for short or stub columns), where the member will never reach the elastic critical buckling load $\mathrm{N}_{\mathrm{cr}}$. Thus, it is necessary to introduce a plasticity criterion, which can be expressed as follows:

$\frac{\mathrm{N}}{\mathrm{A}(\mathrm{x})}+\frac{\mathrm{M}(\mathrm{x})}{\mathrm{W}(\mathrm{x})} \leq \sigma_{\mathrm{f}}$ or

$\mathrm{N}+\frac{\mathrm{A}(\mathrm{x})}{\mathrm{I}(\mathrm{x})} \mathrm{z}(\mathrm{x}) \mathrm{M}(\mathrm{x}) \leq \sigma_{\mathrm{f}} \mathrm{A}(\mathrm{x})$ or

$\mathrm{N} \leq \sigma_{\mathrm{f}} \mathrm{A}(\mathrm{x})-\frac{\mathrm{z}(\mathrm{x})}{\mathrm{i}(\mathrm{x})^{2}} \mathrm{M}(\mathrm{x})=\sigma_{\mathrm{f}} \mathrm{A}(\mathrm{x})-\frac{\mathrm{z}(\mathrm{x})}{[\mathrm{i}(\mathrm{x}) / \ell]^{2}} \cdot \frac{\mathrm{M}(\mathrm{x})}{\ell^{2}}$

or,

finally

$\mathrm{N} \leq \sigma_{\mathrm{f}} \mathrm{A}(\mathrm{x})-\mathrm{z}(\mathrm{x}) \lambda^{2}(\mathrm{x}) \frac{\mathrm{M}(\mathrm{x})}{\ell^{2}}$

where $\mathrm{z}(\mathrm{x})$ is the distance of the extreme fiber of the member's cross-section at position $\mathrm{x}$, and $\lambda(\mathrm{x})$ is the slenderness of the member.

\section{INITIAL IMPERFECTIONS}

Initial imperfections may appear on a member due to a bad stacking during the transportation of steel members and, rather rarely, due to constructional causes. In any case, initial imperfections have usually a form resembling to a parabolic type that can be expressed as follows:

$\mathrm{w}_{\mathrm{o}}(\mathrm{x})=-4 \mathrm{f}\left(\frac{\mathrm{x}}{\ell}\right)^{2}+4 \mathrm{f} \frac{\mathrm{x}}{\ell}$

where $\mathrm{f}$ is the maximum deformation at $\mathrm{x}=\ell / 2$.

\section{CROSS-SECTIONAL TYPES}

The beam-column cross section may have one of the forms shown in Fig. (2). In Fig. (2a), one can see a column the cross-section of which changes parabolically. In Fig. (2b) a tapered member is shown, while in Fig. (2c) one can see a member composed by two tapered parts with different length. Finally, in Fig. (2d), one can see a stepped beamcolumn.

In the cases of Fig. (2a,b and $\mathbf{c}$ ), the cross-section at any point $\mathrm{x}$ has usually constant flanges $\left(\mathrm{b} \cdot \mathrm{t}_{\mathrm{f}}\right)$ but a web with variable depth $\mathrm{z}$.

In all the above cases, the following relation is valid:

$\mathrm{I}(\mathrm{x})=\frac{4}{3} \cdot \mathrm{t}_{\mathrm{w}} \cdot \mathrm{z}^{3}(\mathrm{x})+2 \mathrm{~b} \cdot \mathrm{t}_{\mathrm{f}} \cdot\left[\mathrm{z}(\mathrm{x})+\frac{\mathrm{t}_{\mathrm{f}}}{2}\right]^{2}$

\section{The Parabolic Beam}

If the web depth $\mathrm{z}$ or the moment of inertia $\mathrm{I}(\mathrm{x})$ change parabolically, it will be (see Fig. 2a and 2e):
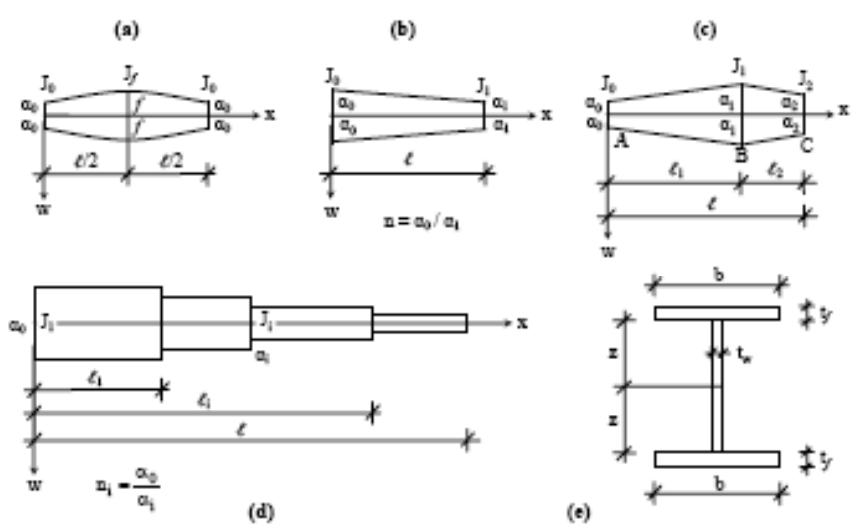

Fig. (2). Steel members with different forms.

$\mathrm{z}(\mathrm{x})=4\left(\alpha_{\mathrm{o}}-\mathrm{f}\right)\left(\frac{\mathrm{x}}{\ell}\right)^{2}-4\left(\alpha_{\mathrm{o}}-\mathrm{f}\right) \cdot \frac{\mathrm{x}}{\ell}+\alpha_{\mathrm{o}}$

$\mathrm{I}(\mathrm{x})=4\left(\mathrm{I}_{\mathrm{o}}-\mathrm{I}_{\mathrm{f}}\right)\left(\frac{\mathrm{x}}{\ell}\right)^{2}-4\left(\mathrm{I}_{\mathrm{o}}-\mathrm{I}_{\mathrm{f}}\right) \cdot \frac{\mathrm{x}}{\ell}+\mathrm{I}_{\mathrm{o}}$

\section{The Tapered Beam}

For the case of Fig. (2b), and assuming that $\alpha_{1}=n \alpha_{0}$, we will have:

$\mathrm{z}(\mathrm{x})=\alpha_{\mathrm{o}}(\mathrm{n}-1) \cdot \frac{\mathrm{x}}{\ell}+\alpha_{\mathrm{o}}$

\section{The Beam with Two Tapered Parts}

For the case of Fig. (2c), and assuming that $\alpha_{1}=n_{1} \cdot \alpha_{0}$ and $\alpha_{2}=\mathrm{n}_{2} \cdot \alpha_{1}$ we will have:

$$
\begin{aligned}
& \mathrm{z}(\mathrm{x})=\alpha_{\mathrm{o}}\left(\mathrm{n}_{1}-1\right) \cdot \frac{\mathrm{x}}{\ell_{1}}+\alpha_{\mathrm{o}} \text { for } 0 \leq \mathrm{x} \leq \ell_{1} \\
& \mathrm{z}(\mathrm{x})=\mathrm{n}_{1} \alpha_{\mathrm{o}}\left(\mathrm{n}_{2}-1\right) \cdot \frac{\mathrm{x}-\ell_{1}}{\ell_{1}}+\mathrm{n}_{1} \alpha_{\mathrm{o}} \text { for } \ell_{1} \leq \mathrm{x} \leq \ell
\end{aligned}
$$

For members consisting of two tapered parts we note that the discontinuity at $\mathrm{x}=\ell_{1}$, affects the results obtained by using some commercial mathematical manipulators. For the case of a beam composed by two parts with lengths $\ell_{1}$ and $\ell_{2}$, and flanges $\mathrm{AB}$ and $\mathrm{BC}$ (Fig. 2c) that have the same inclination, the following approaching formula that removes the aforementioned discontinuity is suggested:

$$
\begin{aligned}
& \mathrm{z}(\mathrm{x})=\alpha_{\mathrm{o}}\left[\sqrt{\left[\frac{\mathrm{n}-1}{\ell_{1}} \cdot\left(\mathrm{x}-\ell_{1}\right)\right]^{2}+\frac{1}{10000}}-\left(\mathrm{n}+\frac{1}{10000}\right)\right] \\
& \text { with } \mathrm{n}=\frac{\alpha_{1}}{\alpha_{\mathrm{o}}}
\end{aligned}
$$

\section{The Stepped Beam-Column}

In this case (Fig. 2d) we have:

$$
\mathrm{I}_{\mathrm{i}}(\mathrm{x})=\mathrm{I}_{\mathrm{i}}=\text { const. } \text { for } \sum_{\rho=1}^{\mathrm{i}-1} \ell_{\rho} \leq \mathrm{x} \leq \sum_{\rho=1}^{\mathrm{i}} \ell_{\rho}
$$


Table 1. IPE Steel Profiles

\begin{tabular}{|c|c|c|c|}
\hline Profile & IPE 200 & IPE 400 & IPE 600 \\
\hline \hline $2 \cdot \mathrm{z}(\mathrm{m})$ & 0.183 & 0.373 & 0.562 \\
$\mathrm{~b}(\mathrm{~m})$ & 0.100 & 0.180 & 0.220 \\
$\mathrm{t}_{\mathrm{w}}(\mathrm{m})$ & 0.0056 & 0.0086 & 0.0120 \\
$\mathrm{t}_{\mathrm{f}}(\mathrm{m})$ & 0.0085 & 0.0135 & 0.0190 \\
$\mathrm{~A}\left(\mathrm{~m}^{2}\right)$ & 0.002735 & 0.008068 & 0.01510 \\
$\mathrm{I} \cdot 10^{-4}\left(\mathrm{~m}^{4}\right)$ & 0.213 & 2.559 & 10.604 \\
\hline
\end{tabular}

Table 2. HEB Steel Profiles

\begin{tabular}{|c|c|c|c|}
\hline Profile & HEB 200 & HEB 400 & HEB 600 \\
\hline \hline $2 \cdot \mathrm{z}(\mathrm{m})$ & 0.170 & 0.352 & 0.540 \\
$\mathrm{~b}(\mathrm{~m})$ & 0.200 & 0.300 & 0.300 \\
$\mathrm{t}_{\mathrm{w}}(\mathrm{m})$ & 0.0090 & 0.0135 & 0.0155 \\
$\mathrm{t}_{\mathrm{f}}(\mathrm{m})$ & 0.0150 & 0.0240 & 0.0300 \\
$\mathrm{~A}\left(\mathrm{~m}^{2}\right)$ & 0.00753 & 0.01915 & 0.02637 \\
$\mathrm{I} \cdot 10^{-4}\left(\mathrm{~m}^{4}\right)$ & 0.5871 & 6.071 & 18.688 \\
\hline \hline
\end{tabular}

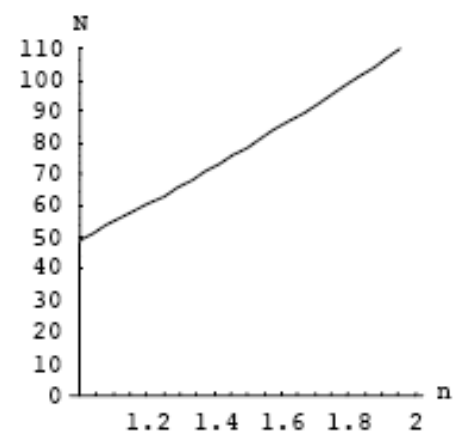

(a)

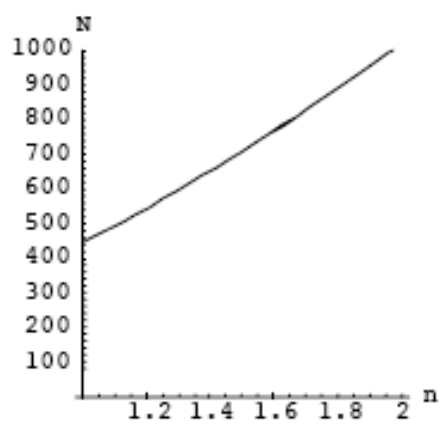

(b)

Fig. (3). Convergence study for IPE 200, (a) L=30m and (b) $\mathrm{L}=10 \mathrm{~m}$.

\section{NUMERICAL RESULTS}

In order to study the buckling behavior of steel members with non-uniform cross section, we will use members having at $\mathrm{x}=0$ the characteristic properties given by the following Tables 1 and $\mathbf{2}$ which refer to IPE and HEB standard profiles, respectively, according to European Norms for characterization of standard steel sections.

\section{CONVERGENCE STUDY OF THE METHOD}

Studying first the convergence of the method, we see from the plots of Fig. (3) that the results arising from a solution using the first three eigenshapes and another solution using the first six eigenshapes coincide fully. We notice only
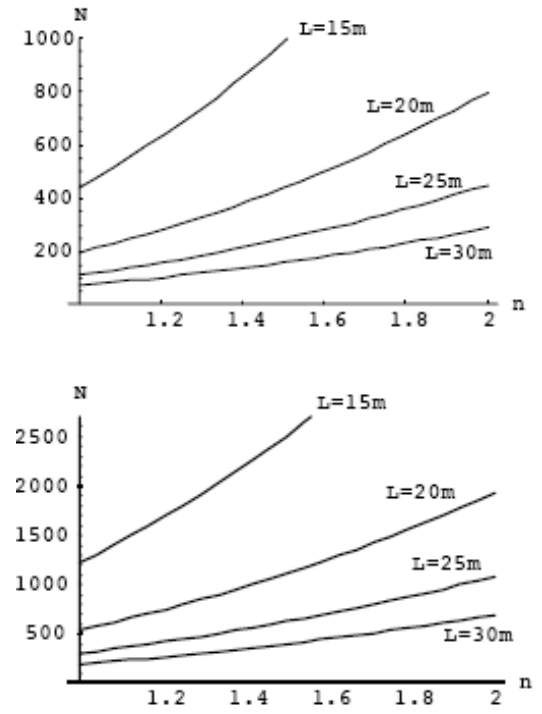

Fig. (4). Critical loads for parabolic beams made from (a) IPE200 and (b) HEB200 profiles with lengths 15, 20, 25 and 30m.

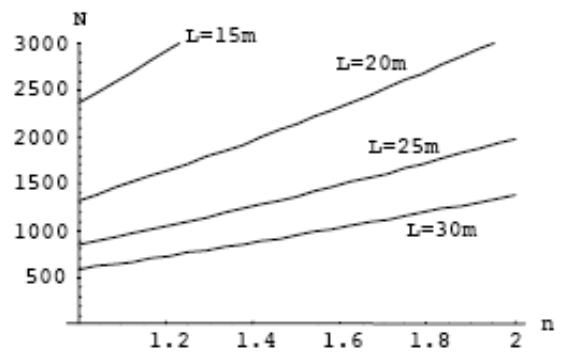

(a)

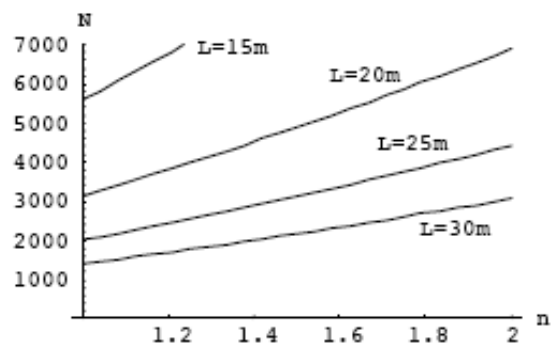

Fig. (5). Critical loads for tapered beams made from (a) IPE400 and (b) HEB400 profiles with lengths 15, 20, 25 and 30m.

a slight mismatch less than $0.1 \%$ for values of $\mathrm{n} \cong 1.7$ and for beam length $\mathrm{L}=10 \mathrm{~m}$. This very small difference is probably due to the numerical approach of the program used.

We see also that for $n=1$ we recover the Euler critical buckling loads $\mathrm{P}_{\mathrm{cr}}=\pi^{2} \mathrm{EI} / \mathrm{L}^{2}$ corresponding to simply supported axially compressed columns.

\section{DETERMINATION OF THE CRITICAL LOAD}

Applying the proposed formulae, we determine the critical loads $\mathrm{N}_{\mathrm{cr}}$ versus $\mathrm{n}$ for columns with different lengths and cross-sectional types.

In the following figures, the plots of critical loads are shown for beams with parabolic form made from IPE200 and HEB200 standard profiles (Fig. 4), with tapered form made from IPE400 and HEB400 profiles (Fig. 5), for a beam 


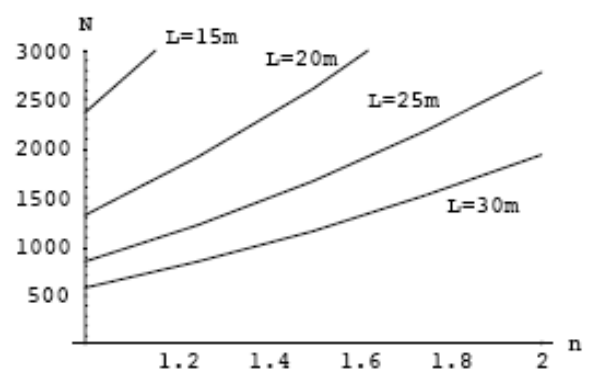

(a)

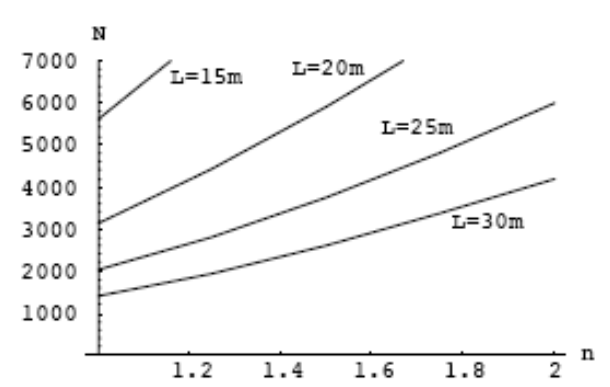

(b)

Fig. (6). Critical loads for beams with two tapered pieces made from (a) IPE400 and (b) HEB400 profiles with lengths 15, 20, 25 and $30 \mathrm{~m}$.
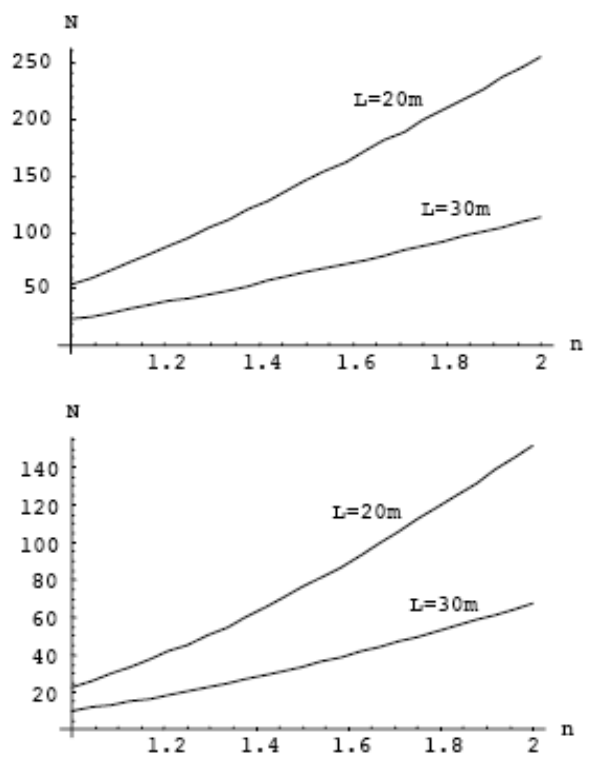

(a)

Fig. (7). Critical loads for a stepped beam made from IPE200 with total length 20 and $30 \mathrm{~m}$, with (a) $\mu_{1}=1, \mu_{2}=1$ and (b) $\mu_{1}=5, \mu_{2}=3$.

composed by two tapered parts (Fig. 6), and for a stepped beam (Fig. 7) composed by three equal length parts with equal $\mathrm{n}_{\mathrm{i}}=\mathrm{n}$, where the part with the smaller cross-section is IPE200 and is loaded by a force $N$ at $\ell$, by $P_{1}=\mu_{1} N$ at $\ell_{1}$ and by $\mathrm{P}_{2}=\mu_{2} \mathrm{~N}$ at $\ell_{2}$. $\mu_{2}=3$.

In Fig. (5a) it is $\mu_{1}=0, \mu_{2}=0$, while in Fig. (5b) it is $\mu_{1}=5$,

From Figs (4 to 7 ), we can easily see that the critical loads $\mathrm{N}_{\mathrm{cr}}$ are significantly higher than the ones corresponding to prismatic members (uniform cross-section) depending on the taper ratio $n$. As the taper ratio $n$ increases the critical load also increases for all types of cross-sectional variation.

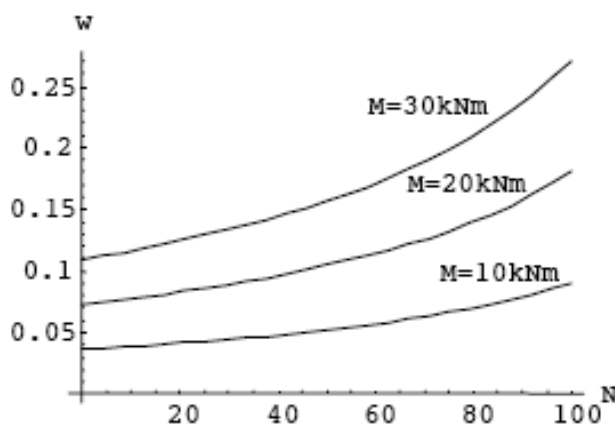

(a)

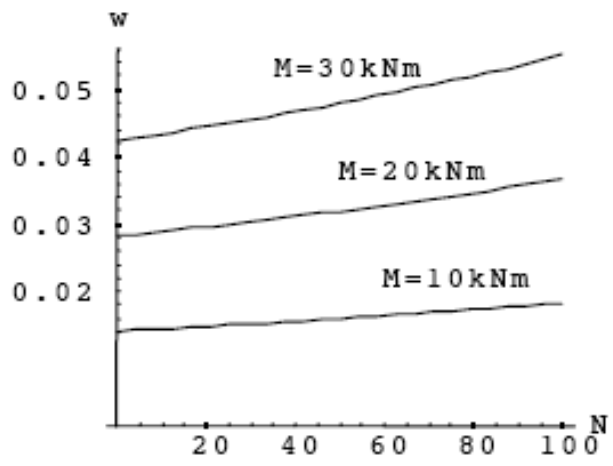

(b)

Fig. (8). Equilibrium paths for a parabolic beam made from IPE200 with (a) $n=1.25$ and (b) $n=2.0$.

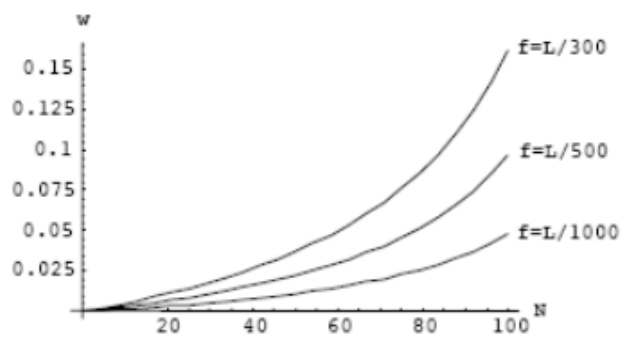

(a)

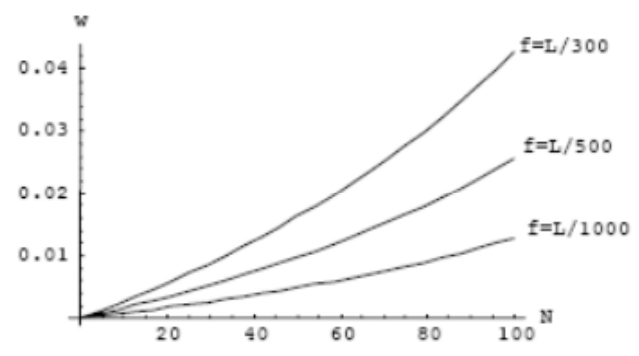

(b)

Fig. (9). Equilibrium paths of a tapered beam with (a) $n=1.25$ and (b) $\mathrm{n}=2.0$ and initial imperfections $\mathrm{f}$.

\section{Equilibrium Paths}

In the plots of Fig. (8), the equilibrium paths versus the axial load $\mathrm{N}$ are shown for a beam with parabolic form, length $20 \mathrm{~m}$ and $n=1.25$ (Fig. 8a) and $n=2$ (Fig. 8b) which is loaded by moments of 10, 20 and $30 \mathrm{kNm}$.

\section{The Effect of Initial Imperfections}

In the plots of Fig. (9), the equilibrium paths versus $\mathrm{N}$ of a tapered beam with length $20 \mathrm{~m}$ and $\mathrm{f}=\mathrm{L} / 300, \mathrm{~L} / 500, \mathrm{~L} / 1000$ with $n=1.25$ (Fig. 9a) or $n=2$ (Fig. 9b) are shown. 

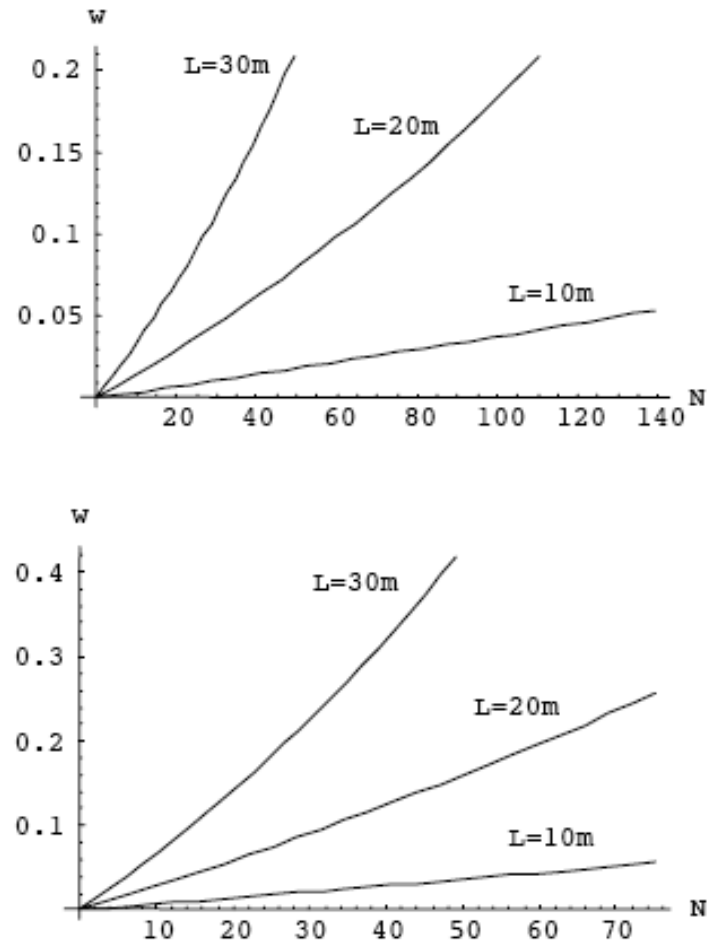

Fig. (10). Equilibrium paths of a parabolic beam loaded eccentrically with (a) $\mathrm{e}=0.5 \mathrm{~m}$ and (b) $\mathrm{e}=1.0 \mathrm{~m}$.

\section{Eccentrically Applied Loads}

Finally, the plots of Fig. (10) show the equilibrium paths for the special case of a parabolic beam with length 10,20 , or $30 \mathrm{~m}$ and $\mathrm{n}=2$, which is loaded by an axial force $\mathrm{N}$ acting eccentrically at $\mathrm{e}=0.5 \mathrm{~m}$ (Fig. 10a) and $\mathrm{e}=1.0 \mathrm{~m}$ (Fig. 10b).

Some of the above results have been verified via the finite element method. More specifically, a tapered beam with lengths $20 \mathrm{~m}$ and $30 \mathrm{~m}$ made from IPE 200 profile and taper ratio $\mathrm{n}=1.5$ has been modeled and analyzed for linear buckling using the SAP-2000 v11 commercial FE code. The deviation between analytical and $\mathrm{FE}$ results is $2.07 \%$ for $\mathrm{L}=20 \mathrm{~m}$ and $1.23 \%$ for $\mathrm{L}=30 \mathrm{~m}$ (Fig. 5a). Moreover, a stepped beam with lengths $20 \mathrm{~m}$ and $30 \mathrm{~m}$ made from IPE 200 profile and taper ratio $\mathrm{n}=1.5$ with $\mu_{1}=\mu_{2}=1$ has also been modeled and analyzed with the same code. In this case, the deviation between analytical and FE results is $1.64 \%$ for $\mathrm{L}=20 \mathrm{~m}$ and $1.15 \%$ for $\mathrm{L}=30 \mathrm{~m}$ (Fig. $7 \mathbf{a})$.

\section{SUMMARY AND CONCLUSIONS}

In this paper, a simple and efficient method for the study of non-uniform steel members with or without imperfections, loaded by axial forces concentrically or eccentrically applied and by moments at its ends or at intermediate points is presented. The governing equation of the problem including all the above parameters is solved by the Galerkin method using the eigenshapes of the member.

The variation of the members' cross-section may be whichever as well as the type of initial imperfections. The accuracy of the method is proven excellent using only the three first eigenshapes. A plasticity criterion is applied in order to predict material failure due to buckling deformation.
The existence of bending moments or intermediate forces reduces not only the critical buckling load, but also the load arising from the failure criterion.

The numerical results and the diagrams presented in this study refer to a number of cross-sections made from IPE and HEB standard profiles that are commonly used in steel structures.

The presented formulae can be easily formulated in a personal computer using one of the available commercial programs (such as Maple, Mathematica, Matlab, etc). Although in this work only the simply supported single-span beam-column is presented, it is obvious that the formulation can be extended to any type of frame members or frames using the corresponding eigenshapes.

The results are presented in the form of diagrams either for the critical buckling loads or for the equilibrium paths, showing the influence of the main member's characteristics, as for example the cross-sectional variation law, the intermediate loads and bending moments or the existing imperfections on the above mentioned buckling loads and equilibrium paths. Although these diagrams are derived for a simply supported beam-column they can be readily employed for the design of steel frames with such members through the use of the equivalent buckling length factor concept.

\section{CONFLICT OF INTEREST}

None declared.

\section{ACKNOWLEDGEMENT}

None declared.

\section{REFERENCES}

[1] S.P. Timoshenko, and J.M. Gere, "Theory of Elastic Stability”, New York: Mc-Graw Hill, 1961.

[2] J. Malets, Trans. ASME, vol. 51, 1925.

[3] J. Malets, Trans. ASME, vol. 54, 1932.

[4] S. Ostwald, Klassiker der exakten Wissenschaften, No 175, Leipzig, 1910.

[5] W. Ono, Mem. Coll. Eng. Kyushu Imp. Univ. Fakuoka, vol. 1, Japan, 1919.

[6] B.E.W. Stedman, Engineering, vol. 98, London, 1914

[7] F. Morley, Engineering, vol. 97, London, 1914.

[8] F. Morley, Engineering, vol. 104, London, 1917.

[9] S.P. Timoshenko, History of Strength of Materials, New York: Mc-Graw Hill, 1953.

[10] F. Bleich, Theory and Berechnung der eisernen Brücken, Berlin, 1924.

[11] A. Marston, Trans. ASCE, vol. 39, 1897.

[12] C. Jensen, Engineering, vol. 85, London, 1908.

[13] F. Lilly, Engineering, vol. 92, London, 1911.

[14] E.H. Salmon, Columns, London, 1925.

[15] N. Dimitrov, "Ermittlung konstanter Ersatzträgheits momente für Druckstäbe mit feränderlichen Querschnitt”, Bauingenieur, vol. 1, p. $208,1953$.

[16] J.W. Harrey, "Buckling loads for stepped columns", J. Struct. Div. ASCE, vol. 90, no. ST2, pp. 201-221, 1964.

[17] C.K.Wang, "Stability of rigid frames with non-uniform members", J. Struct. Div. ASCE, vol. 93, no. ST1, pp. 275-294, 1967.

[18] D.J. Fraser, "Design of tapered member portal frames", J. Constr. Steel Res., vol. 3, no. 3, pp. 20-26, 1983.

[19] T. Galambos, Ed., Guide to Stability Criteria for Metal Structures, $4^{\text {th }}$ ed. Reading: Wiley, New York, 1988.

[20] S.Y. Lee, and Y.H. Kuo, "Elastic stability of non-uniform columns", J. Sound Vib., vol. 148, No. 1, pp. 11-24, 1991.

[21] H.R. Ronagh, and M.A. Bradford, "Elastic distortional buckling of tapered I beams”, Eng. Struct., vol. 16, no. 2, pp. 97-110, 1994. 
[22] A.M. Baptista, and J.P. Muzeau, "Nonlinear buckling of tapered columns", in Proceedings of the $2^{\text {nd }}$ Int. Conf. on coupled instabilities in Metal Structures, 1996, pp. 230-238.

[23] I.G. Raftoyiannis, and J.Ch. Ermopoulos, "Stability of tapered and stepped steel columns with initial imperfections", J Eng. Struct., vol. 27 , no. 8 , pp. 1248-1257, 2005.

[24] R. Gonçalves, and D. Camotim, "On the incorporation of equivalent member imperfections in the in-plan design of steel frames", $J$. Constr. Steel Res., vol. 61, pp. 1226-1240, 2005.

[25] N. Bazeos, and D. Karabalis, "Efficient computation of buckling loads for plane steel frames with tapered members", Eng. Struct., vol. 28, pp. 771-775, 2006.

[26] I.G. Raftoyiannis, G. Stamatopoulos, and J.Ch. Ermopoulos, "Buckling Behavior of Doubly-Tapered Steel Columns Under Axial Compression and Biaxial Bending", in Proceedings of the Int. Colloquium on Stability and Ductility of Steel Structures, SDSS '06, Sept. 6 - 8, CD Proceedings, Lisbon, Portugal, 2006.
[27] R. Adman, and H. Afra, "Exact shape functions of imperfect beam element for stability analysis", Adv Eng. Softw., vol. 38, pp. 576585, 2007.

[28] A.R. Rahai, and S. Kazemi, "Buckling analysis of non-prismatic columns based on modified vibration modes", Commun. Nonlinear Sci. Numer. Simul., vol. 13, pp. 1721-1735, 2008.

[29] L. Xu, and X.H. Wang, "Storey-based columns effective length factors with accounting initial geometric imperfections", Eng. Struct., vol. 30, pp. 3434-3444, 2008.

[30] G.B.I. Rankin, J.C. Leister, and D.J. Robinson, "Novel loading tests on full-scale tapered member portal frames", in Proceedings of the ICE-Structures and Buildings, vol. 162, no. 3, pp. 151-159, 2009.

[31] I.M. El-Aghoury, M. El-Aghouri, and A.H. Salem, "Behaviour of bi-axially loaded thin-walled tapered beam-columns with doubly symmetric sections", Thin-Walled Structures, vol. 47, pp. 15351543, 2009.

(C) Konstantakopoulos et al.; Licensee Bentham Open.

This is an open access article licensed under the terms of the Creative Commons Attribution Non-Commercial License (http://creativecommons.org/licenses/by-nc/3.0/) which permits unrestricted, non-commercial use, distribution and reproduction in any medium, provided the work is properly cited. 